\title{
El cuidado de sí mismo y la personalidad sana
}

RESUMEN: Se presenta un concepto de salud mental como patrón secuencial de acción que contribuye a una experiencia satisfactoria de la vida. En relación con ello, la personalidad psicológicamente sana se define por la capacidad y la disposición para cuidar de sí misma en orden a esa experiencia.

PALABRAS CLAVE: salud mental, personalidad sana, sí mismo, autorregulación

Lady Macbeth ha sido inductora en el asesinato del rey Duncan y ahora, tiempo después, está en trance de muerte mientras el bosque de Birnam, cortado y a lomos de soldados, asciende resueltamente hacia la fortaleza de Dunsinane. No sabemos de qué muere, pero ha perdido la razón, delira, ve visiones, fantasmas. Ni siquiera es seguro que agonice consumida por el remordimiento. Shakespeare se alza por encima de un conocimiento nada más diagnóstico y también por encima del bien y del mal. Lord Macbeth, al que va a alcanzar la espada para morir como un caballero, "con la armadura puesta», le ha preguntado al médico cómo va la paciente. El médico le ha dicho que las visiones que la agitan no le permiten reposar y Macbeth le responde, le exige al médico:

\begin{abstract}
Mental health is considered as a pattern of behavior that contributes to a satisfactory experience in life. Healthy personality is seen as capacity or disposition of self-caring in order to that experience.
\end{abstract}

KEY-WORDS: mental health, healthy personality, self, selfdirection

«En eso la paciente debe administrarse su propia medicina» (Macbeth, acto V, escena 3)

«Curadla, pues. ¿O es que no podéis atender un mal del alma? ¿O arrancar de la memoria una pena arraigada... y limpiar del pecho con antídoto de olvido esa peligrosa materia que abruma el corazón?». Sabe el médico y dice que la señora está perdida de cuerpo y alma: «En estos casos el paciente ha de ser su propio médico».

Lady Macbeth es ahora una enferma mental: no hay que tener repugnancia a esa palabra -y sí cauteloso respeto, prudente temblor ante la condición que yace detrás de ella- a despecho tanto de las censuras merecidamente recaídas sobre el modelo médico de los trastornos psico-patológicos, cuanto del reciente énfasis en destacar que salud no hay más que una, la corporal y física, y que esos trastornos son tan materiales como los del cuerpo, al ser 
función del cerebro (1). Shakespeare ya sabía eso; ya sabía que al «alma» (¡es un decir!) le afecta la materia (¡otro decir!).

Lady Macbeth es a la vez una asesina y se halla ahora trastornada, pero no es lo mismo haber asesinado que haber perdido la razón. Es a la vez una demente y una moribunda, mas no es lo mismo delirar que agonizar. Es una paciente en lo «físico» y en lo «mental», pero una «enfermedad» no se confunde con la otra, igual que por muy unitaria e indivisible que sea la salud una cardiopatía no se confunde con una enfermedad renal. Aviados estaríamos con tratamientos y enfoques sólo holísticos para atajar una peritonitis.

Por boca del médico, Shakespeare compendia toda la sabiduría antigua sobre el caso: en esta condición, en estos trances sólo el paciente puede administrarse su propia medicina. Claro que ése justo es el problema: el paciente -el «cliente», dicho en lenguaje comercial y conductistamente correcto- no puede curarse a sí mismo, es incapaz de ser su propio médico o farmacéutico. Es esta incapacidad la que aquí se va a tomar como esencial característica de la «enfermedad mental»-o, en rigor, de los trastornos de la personalidad- bien a conciencia, como alguna vez ironizó Szasz (2), de que las enfermedades mentales ni son enfermedades ni son mentales.

No son mentales, desde luego, si por «mente» se entiende un alma o «mind», sobre cuya falacia conceptual han disertado Ryle (3) y otros filósofos (4). Sin embargo, de suyo y pese a derivar del latino «mens», el adjetivo «mental» hoy tiene tan poco que ver con una noción mentalista como los propios nombres de «psicología» y «psiquiatría», derivados de «psyché», que en griego es alma. Al igual que lo «psi- cológico», también lo «mental» muy bien puede - $y$ sin duda debe- entenderse como «comportamental».

¿No son enfermedades? Al llamarlas así, se trata por cierto de un lenguaje metafórico. Si se utiliza, hay que hacerlo a sabiendas de estar usando una metáfora. Todo el asunto estriba en si, confrontada con las de «alteración», «desviación»o «anomalía», la metáfora de enfermedad es de todos modos aceptable e incluso preferible: en si lo es al menos para aquellos casos, como el síndrome de Alzheimer, donde el grave deterioro cognitivo forma parte de un hundimiento general de la persona. La desafección a hablar de enfermedad mental, por otro lado, no entraña por fuerza desistir de hablar al menos de «salud mental». Las metáforas, en cualquier caso, pueden convivir; no son incompatibles.

Cualesquiera sean las metáforas o modelos utilizados, sí que importa puntualizar desde el principio que son difusos los límites de la construcción así levantada. El Manual del DSM-IV (5, pág. XXI) lo reconoce en las páginas de introducción: «No existe una definición satisfactoria que especifique límites precisos del concepto de 'trastorno mental' (... y salud física y mental)». Ese carácter difuso se relaciona a su vez con la multiplicidad de criterios que los tratadistas de la psicopatología concuerdan en señalar en el trastorno o anomalía mental o psicopatológica (6-8).

\section{Modelos de vida humana}

La sabiduría clásica, griega y latina, forjó una máxima y un tema que subyace a posiciones y doctrinas $-\gg$ mora- 
ORIGINALES Y REVISIONES

les», si se quiere- tan distintas entre sí como eudemonismo, hedonismo y estoicismo. Es la ética y la sabiduría del «jcuida de tí mismo»!; es, en latín, la «cura sui», el autocuidado. Sabio es aquél que sabe cuidar de sí mismo. Sabiduría es entonces la figura combinada -y en sazón- resultante del cumplimiento de dos exhortaciones también clásicas: el «iconócete a tí mismo!» de la inscripción en el frontispicio de la entrada al oráculo de Delfos; y el «jsé el que eres!» de Píndaro, luego tan caro a Goethe.

Es una tradición que bajo la lente de «tecnologías del yo» ha expuesto recientemente el filósofo Foucault (9). ¿Puede esa tradición recibir carta de naturaleza empírica en una ciencia del comportamiento? No es meterse en camisa de once varas. Hay varias líneas de análisis y de conocimiento que permiten afirmarlo en enfoque no ya sólo de clínica, sino de ciencia básica de la acción y de la personalidad, con el respaldo de sólida investigación ya existente acerca del bienestar personal y en el marco de una teoría -y entronque en una práctica- focalizada en la autoeficacia y la autorregulación.

Existen resonancias del tema clásico del autocuidado, ante todo, en una psicología de orientación humanista o personalista, que ha perfilado los rasgos de la «personalidad saludable» (10), y todavía más, con ambición mayor, los de un nivel superior de excelencia y plenitud en la existencia - «modelos ideales de vida humana» los llama DiCaprio (11)-, que es la madurez, la autorrealización o el pleno devenir actualizado de la potencialidad de la persona.

Da que pensar el hecho de que, en sus dos libros pioneros de psicología de la personalidad, Allport (12-13) dedicara sendos capítulos amplios al tema de la personalidad madura. En el perfil de excelencia que dibuja, Allport caracteriza la madurez personal por la ampliación del «yo», su relación afectuosa con los demás, la seguridad emocional, una percepción conforme a la realidad, aptitudes ante las tareas, conocimiento de sí y visión unificadora de la vida. No es muy distinta la caracterización de Maslow (14) de las personas «autorrealizadas»: con percepción eficaz y cómoda de la realidad, aceptadoras de sí mismas, de los demás y de la naturaleza, espontáneas, centradas en los problemas, autónomas, con buenas relaciones personales y sentido del humor. Y se asemeja a ambos lo que Rogers (15) presenta como meta del deseable «proceso de convertirse en persona» y a lo que invita en eco de Píndaro: llegar a «ser el que uno es», consistente en autodirección, deseo de progreso, apertura a la experiencia, confianza en uno mismo, sentimiento de libertad, espontaneidad.

Ha sido sin duda esta psicología personalista y de vocación pedagógica la que más ha contribuido a abrir un espacio compartido por la ciencia y por el sentido común ilustrado, un espacio donde prospera una amplia literatura divulgativa sobre bienestar, salud y trastorno mental (así, entre otras, las colecciones «Autoayuda y superación» de Grijalbo, «Ojos solares» de Pirámide y «Serenpidity» de Desclée de Brouwer). Es literatura de desigual calidad y valor científico, pero a menudo con juiciosas apreciaciones sobre el tema incluso cuando los autores hablan desde la experiencia profesional o el sentido común y no desde el método científico. 
Los temas predilectos de los humanistas personalidad madura, cabal, realizada- suscitan extrema reserva, por no decir repudio, a quienes se atienen a enfoques metodológicos experimentalistas o bien a posiciones teóricas como las del conductismo radical. Ahora bien, ni conductismo ni tampoco la experimentación poseen el monopolio de una ciencia objetiva del comportamiento o de la personalidad, ni tampoco de la salud y madurez mental y, respectivamente, del trastorno. De hecho es posible una aproximación científica a la madurez humana más plena, la que se manifiesta en la sabiduría, tal como hace un sugestivo volumen coordinado por Sternberg (16). Es éste un tema, por cierto, filosófico y moral en la tradición, al que sin embargo cabe asociarle hoy conocimientos empíricos, de ciencia: sobre el desarrollo humano a lo largo del ciclo vital, sobre la madurez personal y sobre los procesos cognitivos y el manejo de saberes en que la sabiduría consiste.

Lo que a continuación se ensaya obedece al modesto propósito de hacer otro tanto -en bosquejo- sobre un asunto bastante más limitado y en un listón no tan alto de los propósitos y tareas de la existencia humana: sobre la consigna práctica y moral del cuidado de uno mismo; sobre la invitación a cuidarse como consejo que trasciende el testimonio de afecto personal y que se configura como exhortación dictada desde la sabiduría, desde el conocimiento. Se va a proponer que la capacidad de autocuidado es justo lo que caracteriza no ya a la sabiduría, sino pura y simplemente a la «salud mental» propia del adulto: a la integridad personal bajo condiciones ordinarias de la vida, con las dificultades normales del vivir, y no ante la tragedia o la adversidad extrema. El análisis tomaría otro cariz al contemplar la infancia, cuando la capacidad de autocuidado aún no se ha adquirido, y también en el caso de minusvalías graves, donde esa capacidad puede hallarse limitada por circunstancias físicas o mentales. También estos casos pueden ser clarificados desde las claves propuestas a continuación, pero no es posible ahora ni siquiera bosquejar la correspondiente clarificación.

Autocuidado en el sistema de «sí mismo»

Al hablar de la acción y de la capacidad de autocuidado se entiende aquí autocuidarse en orden a una experiencia satisfactoria de la vida. Se sobreentiende además: estilo o repertorio de conducta habitual, capacidad o disposición en orden a gestionar bien esa experiencia, y no siempre conducta concreta aisladamente ejecutada. La persona más capaz puede cometer errores y el más inteligente incurrir en actos estúpidos. Por «mentalmente sano» que alguien sea, puede errar más de una vez en su autocuidado o incluso renunciar a él, hasta con riesgo de la vida, en acto heroico por el bien de otros. Del mismo modo, sin embargo, que no se llamará inteligente a quien sólo realiza conductas estúpidas, de quien jamás lleva a cabo acciones de autoprocura que redunden en su propio bienestar difícilmente será posible mantener que goza de buena salud mental.

El trastorno mental en sentido propio (y no ya el tener problemas, conflictos, crisis o sufrimientos morales: ¿quién no los tiene?) ha de verse en consecuencia como un curso de acción o una práctica de autocuidado deficiente. Y si se solicitan 
términos más apegados a un análisis funcional de la conducta, cabe decir también: es una sucesión de conductas operantes, una pauta persistente de comportamiento, un conjunto de «repertorios básicos de conducta» o de "estilos interactivos personales", que no contribuyen a largo plazo a procurarse una experiencia satisfactoria de la vida. Ahora bien, en la medida en que más allá de conceptos comportamentales, de estilos de conducta y del curso de la acción, hace falta acudir a conceptos de personalidad, es decir, de capacidad y de predisposición, entonces el trastorno no ya del comportamiento (en el sentido del Eje I en el sistema DSM) (5), sino el trastorno de personalidad (en el sentido del Eje II), podrá ser conceptuado como una cierta incapacidad o indisposición personal -más o menos duradera, persistente, $o$ al contrario modificable- respecto a esa autoprocura de una experiencia satisfactoria.

Cuidar de uno mismo es un subgrupo específico dentro de cierta clase de comportamientos: los que tienen por objeto y término a la propia persona que se conduce. Son comportamientos que suelen compendiarse en la noción de «sí mismo" (o self). Se despliegan en un amplio sistema de actividades alrededor de dos principales focos: el autoconocimiento, los procesos cognitivos acerca de uno mismo; y la autoacción, las conductas operantes que -y en la medida en que- revierten en el propio agente (17). $\mathrm{Y}$ forman un sistema de gran relevancia, puesto que el comportamiento autorreferido es autorregulado y autorregulador: en sus entresijos se juegan procesos de decisión, que son de autodeterminación y que constituyen uno de los órdenes en que consiste la «libertad» hu- mana desde un análisis no ya de filosofía, sino de ciencia empírica del comportamiento (18).

Colocar dentro del subsistema comportamental de la autorreferencia la clave de la salud o respectivamente del trastorno mental puede resultar poco popular en un momento en que todavía dominan las interpretaciones sólo adaptativas y sociales del mismo. Está cercano el tiempo, alrededor de 1970, en el que las críticas dominantes reducían a mero nombre y etiqueta toda construcción y clasificación psiquiátrica o psicopatológica sobre el argumento de que es la sociedad la que no sólo define, sino que en gran medida engendra la conducta inadaptada. Ahora bien, que la designación de una conducta como patológica dependa de la sociedad o que ésta se halle en la génesis del trastorno (y ¿cómo no?, todo lo humano es social) no es fundamento bastante para reducirla a una pura construcción social. El análisis psicopatológico no es amortizable en términos psicosociológicos.

Es así, por cierto, en una de sus vertientes. Hay mucho de sociología, de psicología social e incluso de juicio moral en los enfoques psiquiátrico y psicopatológico. Pregunta el conflictivo adolescente de Rumble Fish, de Francis Coppola: «¿Cómo se sabe que uno está loco?». Y le contestan: «Eso nunca se sabe; depende de cuánta gente piensa que lo estás». Hay que observar, sin embargo que, con relativa independencia respecto a cualquier definición social, aunque tampoco del todo al margen de ella, está el dato, no siempre patente y manifiesto, pero irrecusable, de que el individuo puede sentirse bien o mal, reconocer su estancia y vivencia en el mundo -o en un medio so- 
cial determinado-, como apetecible o como indeseable, como positiva, satisfactoria 0 , por el contrario, negativa, frustrante. Esta conciencia de sí -autopercepción con intensas connotaciones afectivas- tiene también, ella misma, una raíz que trasciende al individuo: se elabora, sin duda, a partir de la imagen social de lo deseable y de la percepción que cada cual encuentra en otros acerca de sí mismo; se genera a partir de un aprendizaje social y de reacciones sociales ante la conducta del sujeto. Pero, no menos cierto, incluso en una reducción completa a sociogénesis, aquella autopercepción posee su relativa autonomía, su razón de ser y su derecho a atención práctica y teórica. El caso es que tanto el enfoque descriptivo de las alteraciones de personalidad o de comportamiento, como el de terapia e intervención psicológica, al atender al contraste trastorno / salud mental, contemplan componentes irrenunciablemente individuales, no del todo reducibles a lo social y a la ideología colectiva, ni tampoco elaborados desde la sinrazón, la demencia o la locura.

Georges Mead escribió que el individuo, pese a todo, y con razón, es capaz de hacer frente a la entera sociedad: «Una persona puede llegar a un punto tal en que ha de ir contra todo lo que le rodea; pero para poder hacer eso ha de hablarse a sí mismo con la voz de la razón» (19). Cabe decirlo en otras palabras más próximas al presente argumento: la dimensión de bienestar, de vivencia satisfactoria, de capacidad para ella por parte del sujeto constituye una garantía y salvaguardia tanto para sí mismo cuanto para la noción teórica y la meta práctica de salud mental frente a su disolución en meros términos de una adaptación que sea únicamente encaje o ajuste social. Una persona puede sentirse -y saberse a sí misma- «sana», cargada de razón (y de emoción o experiencia positiva, de pasión), asistida por la voz de la racionalidad (una razón práctica y una «inteligencia emocional»: Goleman (20), Mayer y Salovey (21) (si se quieren incluir una noción hoy justamente en boga) frente a una sociedad entera que al sujeto le declara enfermo, inadaptado o desviado. También, por cierto, y con frecuencia mayor, se da la situación contraria, la de quien, pese a ser juzgado del todo normal por la sociedad, se considera a sí mismo en un estado y vivencia cuyo mejor análogo son las heridas o la enfermedad: hundido en la miseria de un malestar peor que cualquier mal orgánico.

Pertinencia al bienestar y capacidad de gozo

Puede tomarse el bienestar (o a la felicidad) como el mejor referente e hilo conductor para cualquier propuesta relativa a la dimensión de trastorno / salud mental e igualmente, en otro plano más de raíz, a la de trastorno de personalidad / personalidad sana. Ningún otro tópico relativo a esa dimensión ha sido tan estudiado como el bienestar, la satisfacción personal, la felicidad (22-26). La única línea comparable al respecto es la de la adaptación, tal como se da, en concreto, en las conductas de afrontamiento y en sus consecuencias. Pero aun esa línea viene a reducirse a la otra, justo al resaltar que el bienestar -junto con la adaptación y la salud física- resulta de un afrontamiento logrado, mientras que malestar, inadaptación y enfermedad son los tres resultados típicos sea del 
estrés sea de un malogrado afrontamiento (27-28).

No es asimilar salud a bienestar (o felicidad) y trastorno a malestar (o desdicha). Es postular como hipótesis conceptual orientadora que se relacionan, aunque no son idénticos. La suya es una relación no de identidad, sino de pertinencia en un nexo cuya naturaleza es preciso esclarecer. Parece ser la hipótesis sobre la que en sus últimas versiones la introducción del Manual DSM realiza su propia formulación del trastorno, una formulación por cierto biopsicológica y no reductora a lo social o a pautas colectivas de valor: «se trata de una disfunción biológica, psicológica o conductual»; $y$ «esta alteración no sólo está referida a la relación entre el individuo y la sociedad» (6). Se añade una precisión esencial: «asociada a un malestar, a una discapacidad o a un riesgo significativamente aumentado de morir o de sufrir dolor, discapacidad o pérdida de libertad». En esas breves frases es patente la redundancia en dos unidades semánticas: en primer lugar, malestar o sufrimiento, y junto con ello, discapacidad. Si se colocan juntos esos dos elementos, la figura compuesta que aparece es la del trastorno mental como cierta incapacidad de bienestar o fracaso de hecho en conseguirlo.

Se halla eso muy cercano a Freud (29), quien señaló a la terapia la finalidad de restablecer en el sujeto la capacidad de trabajo y de goce; y a Fromm (30), cuando en análogo emparejamiento apunta a la capacidad de amor y de trabajo, capacidad productiva y creativa, como núcleo del arte humano de vivir. Es éste un punto de vista apenas o en nada exclusivo de la teoría freudiana; es inteligible y asumible desde cualquier posición, incluida la conductista, con tal de suavizar el término «capacidad»y sustituirlo por algún otro que despierte menos reticencias: hábitos, repertorios aprendidos, quizá disposiciones.

Salud mental no es cualquier bienestar, ni tampoco el bienestar en sí. Trastorno mental no es tampoco, de suyo, el estado de ánimo deprimido, ansioso, de terror, o de desconexión respecto a la realidad. No es trastorno mental el estado de alucinación tras haber ingerido ciertas sustancias, ni la extrema melancolía tras la pérdida del ser más querido. En general, no se trata del trastorno mental transitorio, eximente o atenuante en los códigos penales, ni tampoco el trastorno no tan transitorio pero deliberadamente inducido y controlado por la persona. El trastorno comienza cuando el sujeto no emprende el curso de acción apropiado para salir de ese estado. No lo emprende porque es radicalmente incapaz de ello o porque no se siente en disposición para ello. El trastorno comienza con la incapacidad, indisposición, mera inercia, inacción o acción disfuncional en orden a modificar tal estado indeseable.

Por otra parte, la capacidad o disposición de que se habla en orden a ser feliz no es la de un goce sólo pasivo; no es la del niño de pecho, a cuya imagen, por otro lado, la sociedad de consumo tiende a reducir al ciudadano consumidor. También esto se halla en juego, por cierto: el gozo recibido. Ser incapaz incluso de gozos y alegrías por otros procuradas es precisamente y sin duda el colmo del trastorno de personalidad, el de quien no sabe disfrutar ni de lo que le viene gratuitamente dado. Pero más allá de esto se está hablando de una capacidad de -y un curso de acción en 
orden a- un gozo activo, autoprocurado, y esto no necesariamente por la busca directa de la felicidad, búsqueda sobre la que Russell (31) advierte que quizá no lleva a ninguna parte, sino como algo que le sobreviene a la acción operante, al vivir activo, aún sin necesidad de proponérselo y como por añadidura.

La salud mental tiene que ver con experiencias, la de bienestar personal o satisfacción en la vida, pero propiamente consiste en comportamientos ordenados a esas experiencias. La cualidad de «psicológicamente sano» o saludable, en rigor, es pertinente no en toda actividad psíquica, de suyo no en la percepción o la memoria, no en las reacciones de placer o dolor, de entusiasmo o de miedo; lo es sólo en el comportamiento operante e instrumental, en la acción propiamente dicha (17), aquella que opera cambios en el entorno o en el propio organismo del agente, cambios capaces de redundar a su vez en experiencias (estimulación, refuerzos, emociones, sentimientos, estados de ánimo) positivas o negativas, gozosas o dolorosas.

Dicha dimensión, además, se ensancha en cierto espesor diacrónico, de duración; acontece y se manifiesta en el tiempo, en la sucesión de acciones y de experiencias de las personas. No el espanto momentáneo en medio de una catástrofe, ni la embriaguez ocasional en una noche loca, sino el cepo duro de una fobia resistente o de una adicción dañina e invencible, donde el sujeto está atrapado y que le incapacita para vivir, es lo que constituye referente de las nociones psiquiátricas y psicopatológicas, así como objeto de tratamiento, psicoterapia o prevención.

\section{Salud mental y personalidad sana}

Por salud psicológica, mental o comportamental, ha de entenderse, pues, la gestión habitual de una experiencia grata de la vida por y para el propio sujeto agente. Esta experiencia, a su vez, incluye las sensaciones más a flor de piel, las procuradas por los sentidos externos, y también aquellas otras más profundas, asociadas al sensorio interno y que se organizan en emociones y sentimientos. La salud mental, sin embargo, no es la experiencia vital grata en sí misma -o la dicha, o la felicidad-, sino la acción, la conducta operante, la práctica de gestionársela para uno mismo. No es en sí la experiencia satisfactoria de la vida, porque son muchas las circunstancias externas que pueden generar desdicha o sufrimiento. Exceptuando fakires y estoicos acaso, los humanos no son invulnerables o inmunes a ellas. Por otro lado, la tradición aristotélica, eudemonista y aún más la estoica, senequista, asocia la felicidad a la sabiduría y a la virtud, al obrar acertado: el hombre virtuoso es el hombre feliz, aunque no está del todo claro si se llama felicidad a la acción virtuosa por ella misma o se piensa que de la virtud se sigue siempre y con toda naturalidad la vida feliz. El caso es, sin embargo -y Kant ha puesto el dedo en esa llaga de la condición humana-, que la dicha no le ha sido prometida a la virtud. Sabiduría y virtud -o salud mental si se atiene el análisis a términos comportamentales- no es lo mismo que felicidad o dicha; pero sí que es capacidad de «cura sui», de cuidado de sí mismo, de autoprocura de felicidad en la medida -a veces mínima- en que eso se halla en pro- 
ORIGINALES Y REVISIONES

pias manos. Es, a la postre, «saber vivir» 0 , si se prefiere «amar la vida», pero amarla eficazmente, es decir, ponerla y guardarla a salvo.

Conviene reservar el término de trastorno psicopatológico para el caso y el momento en que la persona no llega a velar por ella misma, a afrontar con mínima eficacia las circunstancias adversas, al menos aquellas dificultades del vivir que forman parte del programa biológico y social de la existencia humana. Otra cosa es la tragedia. La gravedad trágica de la adversidad puede llegar a trastornar, pero también sencillamente a hacer del todo imposible cualquier forma de afrontamiento logrado o eficaz. Bajo circunstancias negativas extremas es difícil mantener no ya el tipo, sino el sano juicio. Buena salud psicológica han mostrado quienes han salido enteros de la tortura, del secuestro, del campo de concentración o del de refugiados, máquinas y espacios psicopatógenos como ningún otro. Las categorías de salud / trastorno mental, sin embargo, tienen su foco central de pertinencia no en los extremos paroxísticos, sino en las zonas templadas medias de la condición humana: en el modo de habérselas con las adversidades y dificultades ordinarias de la vida, en la forma de cuidar de sí en medio de ellas $y$ de procurarse incluso entonces una experiencia vital positiva, de calidad.

El trastorno psicopatológico es una carencia o insuficiencia comportamental en relación con la felicidad y el bienestar, con una experiencia satisfactoria de la vida. En el polo opuesto, el comportamiento saludable -o psicológicamente sano- es aquel que a largo plazo produce la más positiva experiencia para el propio agente.

Lo que en un nivel de análisis se formula como comportamiento psicológicamente saludable puede y debe ser trasladado también a otro plano, el de la personalidad. Puede y debe producirse ese cambio de plano porque la estructura, procesos y funciones de la personalidad son difícilmente reducibles a los de comportamiento. La personalidad no es una mera suma o conjunto de conductas, de estilos o pautas de conducta. Es potencial de comportamiento, posibilidad activa y probabilidad de comportamiento: es, primero, capacidad y luego también propensión, disposición o predisposición. La personalidad tiene que ver, como no puede ser menos, con lo que el sujeto hace $\mathrm{y}$ ha hecho, pero asimismo con lo que es capaz o no de hacer, con lo que está o no dispuesto a hacer, predispuesto, propenso a realizar.

Este punto de vista permite entender bien cuál es la naturaleza específica de los trastornos de personalidad frente a los de solo el comportamiento. Son trastornos o déficits no ya de la acción, sino -más grave- de la capacidad o de la predisposición a ella. Así entendidos, los trastornos de la personalidad, dentro de los psico-patológicos en general, consisten a fin de cuentas en cierta incapacidad, incompetencia o indisposición para vivir. Los distintos trastornos son variedades funcionales o estructurales (32) de esa incapacidad, menor capacidad o indisposición. Hay grados de severidad en ello. Los hay en las variedades de trastorno que, sin perjuicio de su perfil cualitativo, por otra parte se extienden a lo largo de un espacio dimensional continuo de gravedad, sin corte categórico que permita colocar en un lado y hasta un cierto límite la salud mental y en otro el trastorno. Tampoco hay corte categórico entre el simple trastorno de conducta y, 
más allá y más grave, el de personalidad, o entre los déficits funcionales de personalidad, los de un funcionamiento deficiente, y aquellos déficits estructurales, como la esquizofrenia, que consisten no tanto en que la personalidad funcione mal, sino que en rigor y en realidad no existe, no se halla estructurada.

\section{Psicoterapia y autorregulación}

Autocuidado no es autocontrol en el sentido vulgar, más bien peyorativo, de bloqueo o inhibición, ni es obsesión o preocupación por uno mismo, ni tampoco pertinaz introspección que retorna a la interioridad como a núcleo o fuente de vida auténtica o como a presunto paraíso perdido y recuperable en orden a una liberación por el «espíritu». El exceso de autoanálisis, de autoatención, suele ser insano casi siempre. La capacidad de autocuidarse, aquí equiparada a la personalidad saludable, comporta en cambio, esto sí, ejercicio de un comportamiento de control por uno mismo o -por mejor deciruna actividad de autorregulación.

Los primeros análisis del sistema comportamental de autorreferencia y autorregulación datan de los años 70. En esos años surgen propuestas prácticas de introducción de técnicas de autocontrol en el tratamiento y modificación de conducta (33-34). La consagración analítico-teórica de las propuestas clínicas desde entonces en auge se debe, sobre todo, a Bandura (35-36) con un doble postulado: el de un determinismo recíproco entre situación, conducta y persona, a cuyo sistema de «sí mismo» reconoce así una función; y el del principio de autoeficacia como mecanis- mo mediador del resultado positivo que diferentes técnicas conductuales y de psicoterapia llegan a procurar. Desde entonces, la investigación y análisis de la autorregulación ha puesto de relieve el carácter deseable y benéfico de situaciones y acciones en las que el sujeto «controla» o al menos «maneja» algunas de sus contingencias y, por tanto, es «dueño»en algo de la propia vida. Es un control que implica tomar decisiones sobre uno mismo, autodeterminarse, lo que a su vez constituye una de las manifestaciones de la libertad, empírica y no metafísicamente entendida.

En ese marco de investigación y teoría básica adquieren pleno sentido las prácticas de autocuidado, los comportamientos de autogestión de la propia experiencia a largo plazo. Estos constituyen un factor esencial en todo el ancho ámbito de lo que han sido o son la medicina psicosomática, la medicina comporta-mental y también, más reciente, la psicología de la salud. Esos comportamientos desempeñan funciones sustanciales en la conservación y recuperación de la salud tanto física como psíquica o comportamental, en la perseverancia dentro de unos hábitos saludables de vida, en la adherencia al tratamiento, de cualquier naturaleza que éste sea, $y$ en el haz de medidas terapéuticas o de modificación de conducta que comportan muchas estrategias de intervención (37).

Es significativo que, en los últimos decenios, tanto en intervención psicoterapéutica cuanto en modificación de conducta hayan pasado a primer plano las invitaciones a hacer del paciente (o cliente) copartícipe, colaborador y protagonista activo en el proceso; y que técnicas de 
autogestión (38) se utilicen con toda clase de personas, incluso niños y sujetos con retraso mental (39). Estas son ahora crecientemente incorporadas al lado de aquellas otras más tradicionales desensibilización, economía de fichas- que mantienen el control de estímulos y de refuerzos en manos de profesionales e instructores.

Lo que conviene resaltar es que la incorporación de técnicas de autorregulación es algo más que un simple medio en orden a otros fines: establecer o consolidar unos hábitos deseables, contribuir a superar una depresión, eliminar una fobia o la ansiedad generalizada. Es un fin en sí misma y por su propio valor. En cualquier intervención, no ya una meta entre otras, sino la meta, por antonomasia, es la de (contribuir a) hacer capaz al sujeto de gestionar para sí -en autorregulación y autocuidado- una experiencia gozosa de la vida.

En efecto, la finalidad es, en palabras del médico de Macbeth, que la persona «se administre su propia medicina». El problema es justo, por desgracia, que a menudo la persona es incapaz de eso; es incapaz por ella misma, por sí sola; lo es mientras no reciba el suplemento de energía, de potencialidad, que puede venirle de otras personas cercanas o bien -a falta de ellas o por impotencia suya- de un profesional cualificado para ello. Ahí encuentra pleno significado a la vez humano y técnico la intervención del experto, que a menudo es una suplencia, un complemento o prótesis de la insuficiente capacidad del sujeto, pero siempre en orden a hacerle más capaz, a facilitar que llegue a serlo; una intervención, por tanto, que progresiva y paulatinamente ha de irse desvaneciendo (como en la técnica del «fading») para hacerle pasar de un régimen de control sólo externo a unos mínimos de regulación interna, de autodirección.

Hay otros posibles objetos y objetivos de una intervención psicológica que no es ya terapia en sentido propio: la reducción del sufrimiento, la negociación de conflictos interpersonales, la solución de problemas vitales, la orientación, el consejo o asesoramiento, en general. Los profesionales del comportamiento y de la «psique» trabajan por mejorar las condiciones de vida, de experiencia, en todo el rango de ellas, de su calidad. En lo tocante, sin embargo, al eje o plano de salud y trastorno mental y, aún más claridad, al de personalidad sana y trastorno de personalidad, su intervención concierne a una capacidad humana básica, la de autoprocurarse una experiencia satisfactoria, autogestionar calidad en la propia vida. Psiquiatras y psicólogos tratan de -y tratan, a secas- la (in)capacidad de los sujetos para vivir.

\section{La sabiduría de vivir}

Hay quien hace frente a los últimos años de la vida con un sereno «confieso que he vivido", con un reconocimiento $y$ declaración de vida jubilosa, a lo Pablo Neruda. Otros en cambio admiten, con la tristeza de lo ya irreparable, no haber sabido vivir. Hacia el final de su vida confesó y lamentó Borges haber cometido el «pecado de no haber sido feliz». Al hacer melancólico balance en clave de «pecado», estaba dando a entender que pudo haber sido de otro modo; que en su mano estuvo haber obrado de forma diferente. No es para hacer diagnóstico, ahora inútil e im 
posible, acerca de J.L. Borges, a quien sería por otra parte injusto achacarle en juicio póstumo no haber sabido vivir, $o$ acerca de los Borges todos que en la historia han existido y que no llegaron a ser felices en la medida en que pudieron haberlo sido, puesto que tenían todas las circunstancias a su favor. Es para poner el contraste entre salud y trastorno en palabras cotidianas: acierto -o más bien capacidad de aciertoen ser feliz y, en el otro lado, error, malogro, incompetencia o carencia en no serlo.

La mención del escritor genial que no fue feliz, o no lo fue tanto como pudo serlo, sirve en fin para resaltar en claro ejemplo que el logro y la capacidad de vivir, de gestionar con acierto una experiencia grata de la vida, son muy diferentes de otros logros y capacidades: de naturaleza intelectual, artística, de invención, de industria, de gobierno. Tampoco es para recaer en el mito, de aroma romántico, del artista y del poeta como predestinados, si no a la locura o al desquiciamiento por exceso, sí, al menos, a la desgracia o a la tristeza profunda. Es tan sólo para discernir predisposiciones, cursos de acción, de distinta índole y en ese discernimiento poner de manifiesto la naturaleza específica de esa capacidad, disposición, o simple curso de acción que es la salud mental. Verdad es que ha habido genios -Hölderlin, Nietszche, Van Gogh- que acabaron su vida o la vivieron durante mucho tiempo sumidos en el extremo de la alteración o la aflicción. Eso no documenta alguna afinidad entre genialidad y trastorno; pero sí, y ésta es la tesis, pone en evidencia que salud mental e inteligencia -ingenio e incluso genio- son dimensiones independientes una de otra.

\section{BIBLIOGRAFÍA}

(1) Ribes, E., Psicología y salud: un análisis conceptual, Barcelona, Martínez Roca, 1990.

(2) Szasz, T. S., The myth of mental illness, Nueva York, Hoeber, 1961.

(3) Ryle, G., The concept of mind, 1949.

(4) Bunge, M., The mind-body problem, Oxford, Pergamon, 1980.

(5) Asociación Americana de Psiquiatría, Manual diagnóstico y estadístico de los trastornos mentales (DSM-IV), Barcelona, Masson, 1996. p. XXI

(6) Belloch, A., Santín, B. y Ramos, F., «Conceptos y modelos en Psicopatología». En A. Belloch, B. Santín y F. Ramos. (Eds.) Manual de Psicopatología, vol 1, Madrid, McGraw-Hill, 1995. p. XXI

(7) Gradillas, V. Psicopatología descriptiva, Madrid, Pirámide, 1998.

(8) Vázquez, C., «El concepto de conducta anormal», En: F. Fuentenebro y C. Vázquez (Eds.), Psicología médica, Psicopatología y Psiquiatría, Madrid, Interamericana, 1990.

(9) Foucault, M., Tecnologías del yo, Barcelona, Paidós, 1990.

(10) Jourard, S. M. y Landsman, La personalidad saludable, Méjico, Trillas, 1987.

(11) DiCaprio, N. S., Teoría de la personalidad, México, Saunders Interamericana, 1976.

(12)Allport, G. W., Psicología de la personalidad, Buenos Aires, Paidós, 1974.

(13)Allport, G. W., La personalidad: su configuración y desarrollo, Barcelona, Herder, 1974.

(14)Maslow, A. H., El hombre autorrealizado, Barcelona, Kairós, 1976.

(15)Rogers, C. R., El proceso de convertirse en persona, Buenos Aires, Paidós, 1979.

(16)Sternberg, R. J., La sabiduría: su naturaleza, orígenes y desarrollo, Bilbao, Desclée de Brouwer, 1994.

(17)Fierro, A., Manual de Psicología de la personalidad, Barcelona, Paidós, 1996. cap. 4 y 14 
ORIGINALES Y REVISIONES

(18)Fierro, A., Para una ciencia del sujeto. Investigación de la personalidad, Barcelona, Anthropos, 1993. cap. 3

(19)Mead, G., Espíritu, persona y sociedad, Buenos Aires, Paidós, 1972.

(20)Goleman, D., Inteligencia emocional, Barcelona, Kairós, 1996.

(21)Mayer, J. D. y Salovey, P., «What is emotional intelligence», En: P. Salovey y D. Sluyter (Eds), Emotional development, emotional literacy and emotional intelligence. Nueva York, Basic Books, 1997.

(22)Argyle, M., The Psychology of happiness, Londres, Methuen, 1987.

(23)Bradburn, N. M., The structure of psychological well-being, Chicago, Aldine, 1969.

(24)Campbell, A., «Subjective measures of well-being», American Psychologist, 1976, 31, 117-124.

(25)Diener, D., «Subjective well-being», Psychological Bulletin, 1984, 95, 542-575.

(26) Veenhoven, R., Conditions of happiness. Dordrecht, Reidel, 1984.

(27)Lazarus, R. S., y Folkman, S., Estrés y procesos cognitivos. Barcelona, Martínez Roca, 1986.

(28)Fierro, A., "Estrés, afrontamiento y adaptación». En: M.I. Hombrados (comp.), Estrés y salud. Valencia, Promolibro, 1997.

(29) Freud, S., "Análisis terminable e interminable». En: Obras completas, vol. III. Madrid, Biblioteca Nueva, 1968, original de 1936.
(30)Fromm, E., Etica y psico-análisis, Méjico, Fondo de Cultura Económica, 1957.

(31)Russell. B., La conquista de la felicidad, Madrid, Espasa-Calpe, 1991.

(32)Millon, T., Trastornos de la personalidad: más allá del DSM-IV, Barcelona, Masson, 1998.

(33)Goldfried, M. R. y Merbaum, M. (Eds.), Behavior change through self-control, Nueva York, Holt, Rinehart y Winston, 1973.

(34)Meichenbaum, P. H. y Goodman, J., "Training impulsive children to talk to themselves: A means of developing self-control», Journal of abnormal Psychology, 1971, 77, 115-128.

(35)Bandura, A., «Self-efficiency: toward a unifying theory of behavioral change", American Psychologist, 1977, 84, 191-215.

(36)Bandura, A., "The self system in reciprocal determinism», American Psychologist, 1978, 85, 344-358.

(37)Bakal, D. A., Psicología y salud, Bilbao, Desclée de Brouwer, 1996.

(38)Kanfer, F.H., «Métodos de autogestion», En: Kanfer, F.H. y Goldstein, A.P., Cómo ayudar al cambio en psicoterapia, Bilbao, Desclée de Brouwer, 1993.

(39) Wehmeyer, M. L., Keichner, K. y Richards, S., «Principales características de la conducta autodeterminada de las personas con retraso mental». Siglo Cero 1996, 27 (6) 17-24.

\section{* Alfredo Fierro Bardají}

Catedrático de Universidad. Facultad de Psicología. Campus Universitario de Teatinos

29071 - MÁLAGA

Teléfono 952213746

E-mail: fierro@uma.es

Fecha de recepción: 26-I-2000 